\title{
Gender and age differences in the prevalence and associated factors of metabolic syndrome among children and adolescents in South Korea
}

\author{
Jihea Choi ${ }^{1}$, Tae Woong Yoon ${ }^{2}$, Min Heui Yu ${ }^{2}$, Dae Ryong Kang ${ }^{3}$, Sarah Choi ${ }^{4}$ \\ ${ }^{1}$ Assistant Professor, Department of Nursing, Yonsei University Wonju College of Medicine, Wonju; ${ }^{2}$ Researcher, Department of Biostatistics, Yonsei University \\ Wonju College of Medicine, Wonju; ${ }^{3}$ Professor, Department of Precision Medicine and Biostatistics, Yonsei University Wonju College of Medicine, Wonju, Korea; \\ ${ }^{4}$ Associate Professor, School of Nursing, University of California in Los Angeles, CA, USA
}

Purpose: This study examined the prevalence of metabolic syndrome (MetS) in South Korean children and adolescents by gender and age and analyzed gender-specific factors associated with MetS. Methods: This study used data on children aged 10-18 years from the Korea National Health and Nutrition Examination Survey (KNHANES) from 2010 to 2015. Analyses included descriptive statistics, the independent t-test, the $x^{2}$ test, and univariate logistic regression analysis $(p<.050)$. Results: The prevalence of MetS was $4.8 \%$ in boys and $3.4 \%$ in girls. The prevalence was higher in girls up to the age of 12 , but higher in boys who were 13 or older. Abdominal obesity was frequent in girls, whereas low high-density lipoprotein cholesterol (HDL-C) and elevated blood pressure were more common in boys. Higher body mass index, waist-to-height ratio, waist circumference, blood pressure, triglycerides, HDL-C, perceived "fat" body shape, and weight loss efforts were associated with MetS in both genders. Increasing age, having one meal per day, and weight maintenance were associated factors unique to boys. Fasting plasma glucose, familial medical history of low HDL-C, and perceived "thin" body shape were associated factors in girls. Conclusion: Gender and age differences should be considered in the risk assessment and prevention of MetS.

Key words: Adolescent; Child; Metabolic syndrome; Prevalence

\section{Corresponding author \\ Dae Ryong Kang}

Department of Precision Medicine and Biostatistics, Yonsei University Wonju

College of Medicine, 20 Ilsan-ro, Wonju 26426, Korea

TEL: +82-33-742-0929

FAX: $+82-33-743-9490$

E-MAIL: dr.kang@yonsei.ac.kr

Received Jan 22, 2021

Revised Mar 8, 2021

Accepted Mar 30, 2021

\section{INTRODUCTION}

Metabolic syndrome (MetS) is a strong risk factor for type 2 diabetes and atherosclerotic cardiovascular disease, which have high rates of morbidity and mortality in adults [1]. Recent studies confirmed that the pathological process of MetS starts in childhood and adolescence [2,3]. Those previous studies clearly showed that child and adolescent obesity tend to persist into adulthood. Consequently, the serious effects of clustering cardiovascular risk factors associated with obesity and insulin resistance in children and adolescents should not be overlooked [1-3]. Therefore, early diagnosis and prevention of MetS in childhood and adolescence are critical to preventing MetS and related chronic diseases in adulthood.

The prevalence of MetS is affected by various factors such as age, gender, race/ethnicity, family history, and other socioeconomic characteristics such as economic status $[4,5]$. In particular, due to hormonal changes during puberty, insulin re- sistance may have different effects on metabolic components by gender and age [6]. For example, the prevalence of MetS is higher in females among adults in general [7], but higher in males among children and adolescents [4]. The unique associated factors of MetS prevalence and its patterns of change by gender and age should be identified among children and adolescents for better risk assessment and more effective prevention strategies. Childhood and adolescence are also critical developmental stages during which physical, psychological, social, and cultural factors influence gender-specific body image and self-identity [8]. The relationship between body weight and body image cannot be ignored, since poor body image is associated with unhealthy behavior formation in children and adolescents [8]. Previously published studies have highlighted the differences in MetS prevalence according to gender, but they did not analyze the characteristics of changes in prevalence with age in each gender. Considering the unique, gender-specific characteristics of physical growth and devel- 
opmental changes in children and adolescents, it is very important to take gender and age differences into account to understand the effect of those changes on the prevalence of MetS and provide tailored management to children and adolescents. Therefore, understanding gender- and age-specific risk factors in this population will help guide MetS screening practices and establish effective health practice guidelines for risk assessment and prevention of MetS among children and adolescents.

The modified National Cholesterol Education Program Adult Treatment Panel III (NCEP-ATP III) for children and adolescents is a widely used diagnostic criterion in South Korea and other countries [9]. Based on the modified NECPATP III criteria, the prevalence of MetS among South Korean children and adolescents was 6.2\% in 2008-2014 [10] and 6.5\% in 2015 [11], compared with $7.1 \%$ in 2001 [12]. Even though MetS prevalence decreased during the observed period, serious concerns have been raised regarding the steadily rising prevalence $(11.2 \%$ in $2008,17.3 \%$ in 2017$)$ of childhood obesity in South Korea [13]. Furthermore, research using National Health and Nutrition Survey data, both in South Korea and internationally $[10,11,14]$, has confirmed that a high body mass index (BMI) is the most significant factor affecting the prevalence of MetS in children and adolescents; therefore, BMI should be used as an important indicator of MetS-related health problems in children and adolescents $[10,11,14]$. In addition, early-onset metabolic abnormalities resulting from childhood obesity showed a strong relationship with a higher prevalence of type 2 diabetes mellitus, MetS, and premature atherosclerosis in adulthood than in non-obese children [2].

Therefore, the early detection and management of MetS in children and adolescents, informed by its most significant and predictable associated factors, can have a long-term impact on health outcomes in adulthood. MetS should, however, be understood in terms of the complex effects of physical, psychological, and lifestyle characteristics and not just as a phenomenon linked to BMI. The purpose of this study was to investigate the prevalence of MetS by gender and age and genderspecific factors associated with MetS in South Korean children and adolescents from a multifaceted perspective, including physical, psychological, and lifestyle characteristics, using a national survey dataset from the Korea National Health and Nutrition Examination Survey (KNHANES) from 2010 to 2015.

\section{METHODS}

Ethics statement: This study was a secondary analysis of existing data and did not require institutional review board approval or informed consent.

\section{Study Design}

This secondary data analysis is a cross-sectional descriptive correlational study. We used the KNHANES fifth and sixth waves from 2010 to 2015 to identify the prevalence of MetS in Korean children and adolescents and factors associated with MetS.

\section{Data Source and Study Population}

The KNHANES is a national survey system that has evaluated the health and nutritional status of adults and children over the age of 1 in South Korea every 3 years since 1998. The Division of Chronic Disease Surveillance, Korea Centers for Disease Control and Prevention (http://knhanes.cdc.go.kr) conducts the survey using a multi-stage clustered probability design. The data include socioeconomic status, health-related behaviors, quality of life, healthcare utilization, anthropometric measures, biochemical and clinical profiles for non-communicable diseases, and dietary intake information. The survey includes health interviews, nutritional surveys, and physical examinations [15]. In this study, the fifth-wave data collected from 2010 to 2012 and the sixth-wave data collected from 2013 to 2015 were used. To analyze the prevalence of MetS, the fifth- and sixth-wave data were integrated after factoring for time differences in data collection by applying an integrated weight calculated by each wave's weight according to the KNHANES analysis guidelines. To consider the characteristics of KNHANES data and to reflect the characteristics of children and adolescents, subjects ages 10 to 18 years of age at the beginning of the survey were included in this study. The analysis of 6 years of data (2010-2015) was approved by the Korea Disease Control and Prevention Agency (Korea National Approval Statistics, No.117002).

The total number of subjects aged 10-18 years out of the total number of subjects assessed each year in the KNHANES was 1,076 out of 8,958 in 2010, 942 out of 8,518 in 2011, 900 out of 8,058 in 2012,959 out of 8,018 in 2013, 718 out of 7,550 in 2014, and 748 out of 7,380 in 2015. A total of 5,343 children and adolescents (2,859 boys, 2,484 girls) were identified as potential candidates for this study. However, data on anthropometric variables relevant to MetS were missing for 1,194 subjects (633 boys, 561 girls). Therefore, the present study included a total of 4,149 children and adolescents (2,226 boys, 1,923 girls). Following the data handling guidelines of the KNHANES for representing the characteristics of the South Korean population based on collected data, the authors estimated the number of Korean children and adolescents from the sample size using an adjusted complex sampling weight based on 2010 Population and Housing Census data. As a result, the sample 
subjects of this study represented an estimated 4.6 million (2.4 million boys, 2.1 million girls) South Korean children and adolescents.

\section{Definition of Metabolic Syndrome and Study Variables}

MetS was defined based on guidelines from the modified NCEP ATP III [16]. Participants who met at least three of the following parameters were diagnosed with MetS: $\geq 90^{\text {th }}$ percentile (age, gender-specific) as assessed by waist circumference (WC) for obesity, $\geq 90^{\text {th }}$ percentile (age, gender, heightspecific) for blood pressure (BP), a triglycerides (TG) level $\geq$ $110 \mathrm{mg} / \mathrm{dL}$, a high-density lipoprotein (HDL-C) level $\leq 40$ $\mathrm{mg} / \mathrm{dL}$, and a fasting plasma glucose (FPG) level $\geq 110 \mathrm{mg} / \mathrm{dL}$. We defined high WC (age, gender-specific) and high BP (age, gender, height specific) as $\geq 90^{\text {th }}$ percentile based on the 2007 Korean children growth chart [17].

All anthropometric variables were obtained by trained personnel for each year of the KNHANES. Body weight was measured to the nearest $0.1 \mathrm{~kg}$ on a medical balance scale. Height was measured to the nearest $0.1 \mathrm{~cm}$ with a portable stadiometer. BMI was calculated as weight divided by height squared. WC was measured at the midpoint between the lowest margin of the rib and the uppermost lateral border of the iliac crest during expiration, using a flexible tape measure during minimal respiration. BP was measured on the right arm using a mercury sphygmomanometer after the subject had rested for 5 minutes in a seated position. Systolic blood pressure (SBP) and diastolic blood pressure (DBP) were measured in triplicate, and the second and third measurements were averaged and used in the analyses. Biochemical data (TG, HDL-C, and FPG) were analyzed using a blood specimen taken from each participant after overnight fasting. The samples were transported to a central laboratory after preparation and analyzed within 24 hours [15].

KNHANES health interview data on demographic variables (age, household income), family medical history (hypertension, hypertriglyceridemia, low HDL-C, diabetes mellitus), lifestyle (smoking, alcohol drinking, walking hours per week, frequency of meals per day, weight control efforts over the past year, sleeping hours per day), and psychological variables (perceived body shape, perceived stress level) were included in this study. Family medical history of a condition was determined if a subject's father or mother met the criteria for any of the following conditions: (1) diabetes mellitus: FPG $\geq$ $126 \mathrm{mg} / \mathrm{dL}$, taking diabetes medication or insulin injections, or having a medical diagnosis; (2) hypertriglyceridemia: TG level $\geq 200 \mathrm{mg} / \mathrm{dL}$ after overnight fasting; (3) hypertension: $\mathrm{SBP} \geq 140 \mathrm{mmHg}$ or $\mathrm{DBP} \geq 90 \mathrm{mmHg}$ or taking hypertension medication, and (4) low HDL-C: HDL-C level $<40 \mathrm{mg} / \mathrm{dL}$.

\section{Ethical Considerations}

This study was approved by the research ethics committee from the institution to which the research director belongs (No. CR317341).

\section{Statistical Analysis}

Since the KNHANES uses a complex sampling design, data were analyzed by applying the final weight calculated by accounting for the complex survey design, survey nonresponse, and post-stratification to increase the representativeness and accuracy of the estimates of the South Korean population. The collected data were analyzed using SAS version 9.4 (SAS Institute Inc., Cary, NC, USA). First, the differences between boys' and girls' characteristics were analyzed using the independent t-test and the Rao-Scott $x^{2}$ test. The results were presented as mean, standard error, frequency, and percentage. Second, the estimated differences in the prevalence of MetS in boys and girls were analyzed using the Rao-Scott $x^{2}$ test. Third, the prevalence rate of MetS by age in boys and girls was calculated as a percentage. Lastly, univariate logistic regression analysis was performed to determine the odds ratio (OR) with a $95 \%$ confidence interval (CI) for associations with the prevalence of MetS in children and adolescents in this exploratory study. Univariate logistic regression analysis was used for two reasons. First, the KNHANES dataset was mainly composed of questionnaire items focusing on adulthood diseases, so the variables required to assess MetS-related physical, psychological, and lifestyle characteristics (e.g., data on pubertal stages) were limited or missing altogether. Second, as mentioned in previous studies [18,19], the explanatory power of BMI for the prevalence of MetS was so powerful that it made other factors meaningless. For these reasons, the authors decided to use univariate logistic regression analysis to identify the influence of each variable reflecting physical, psychological, and lifestyle characteristics on the prevalence of MetS in children and adolescents. Statistical significance was determined by a two-tailed $p$-value $<.050$, and the normality of the distribution of all variables was tested before the statistical analysis.

\section{RESULTS}

\section{Weighted Values of the Baseline Characteristics of the Study Population by Gender}

The study population's baseline characteristics by gender are shown in Table 1 . The mean age of study participants was 14.3 years old. BMI, waist-to-height ratio (waist/height; WHtR), 
Table 1. Baseline Characteristics of the Study Population $(N=4,149)$

\begin{tabular}{|c|c|c|c|c|c|}
\hline \multirow[t]{2}{*}{ Variables } & $\begin{array}{c}\text { Total } \\
\left(N=4,149,4.6 \mathrm{~m}^{*}\right)\end{array}$ & $\begin{array}{c}\text { Boys } \\
\left(n=2,226,2.4 m^{*}\right)\end{array}$ & $\begin{array}{c}\text { Girls } \\
\left(\mathrm{n}=1,923,2.1 \mathrm{~m}^{*}\right)\end{array}$ & \multirow[t]{2}{*}{$x^{2}$ or $\mathrm{t}$} & \multirow[t]{2}{*}{$p$} \\
\hline & $N(\%)$ or $\mathrm{M} \pm \mathrm{SE}$ & $\mathrm{n}(\%)$ or $\mathrm{M} \pm \mathrm{SE}$ & $\mathrm{n}(\%)$ or $\mathrm{M} \pm \mathrm{SE}$ & & \\
\hline \multicolumn{6}{|l|}{ Demographic } \\
\hline $\begin{array}{c}\text { Age (year) } \\
10-12 \\
13-15 \\
16-18\end{array}$ & $\begin{array}{c}14.3 \pm 0.1 \\
1,174(28.3) \\
1,421(34.2) \\
1,554(37.5)\end{array}$ & $\begin{array}{l}14.3 \pm 0.1 \\
628(28.2) \\
779(35.0) \\
819(36.8)\end{array}$ & $\begin{array}{l}14.3 \pm 0.1 \\
546(28.4) \\
642(33.4) \\
735(38.2)\end{array}$ & $\begin{array}{l}0.45 \\
1.01\end{array}$ & $\begin{array}{l}.656 \\
.604\end{array}$ \\
\hline $\begin{array}{l}\text { Household income } \\
\text { Low }(\leq 25 \%, 1,160,000 \text { won }) \\
\text { Middle }(>25 \& \leq 75 \%) \\
\text { High }(>75 \%, 2,750,000 \text { won })\end{array}$ & $\begin{array}{r}544(13.1) \\
2,460(59.3) \\
1,145(27.6)\end{array}$ & $\begin{array}{r}267(12.0) \\
1,318(59.2) \\
641(28.8)\end{array}$ & $\begin{array}{r}277(14.4) \\
1,142(59.4) \\
504(26.2)\end{array}$ & 5.34 & .069 \\
\hline $\begin{array}{l}\text { Anthropometric } \\
\text { BMI }\left(\mathrm{kg} / \mathrm{m}^{2}\right) \\
\text { WHtR }(\%) \\
\text { WC }(\mathrm{cm}) \\
\text { SBP }(\mathrm{mmHg}) \\
\text { DBP }(\mathrm{mmHg})\end{array}$ & $\begin{array}{r}20.89 \pm 0.07 \\
0.34 \pm 0.00 \\
70.11 \pm 0.20 \\
107.69 \pm 0.21 \\
66.31 \pm 0.19\end{array}$ & $\begin{array}{c}21.16 \pm 0.10 \\
0.35 \pm 0.00 \\
72.10 \pm 0.28 \\
110.04 \pm 0.29 \\
66.73 \pm 0.26\end{array}$ & $\begin{array}{c}20.58 \pm 0.10 \\
0.33 \pm 0.00 \\
67.83 \pm 0.25 \\
104.70 \pm 0.27 \\
65.83 \pm 0.23\end{array}$ & $\begin{array}{r}4.10 \\
10.17 \\
11.62 \\
13.44 \\
2.80\end{array}$ & $\begin{aligned}<.001 \\
<.001 \\
<.001 \\
<.001 \\
\quad .005\end{aligned}$ \\
\hline $\begin{array}{l}\text { Biochemical } \\
\text { TG (mg/dL) } \\
\text { HDL-C (mg/dL) } \\
\text { FPG (mg/dL) }\end{array}$ & $\begin{array}{l}84.25 \pm 1.02 \\
51.25 \pm 0.22 \\
89.99 \pm 0.18\end{array}$ & $\begin{array}{l}83.50 \pm 1.39 \\
49.91 \pm 0.26 \\
90.38 \pm 0.19\end{array}$ & $\begin{array}{l}85.11 \pm 1.32 \\
52.79 \pm 0.29 \\
89.54 \pm 0.29\end{array}$ & $\begin{array}{l}0.90 \\
8.21 \\
2.73\end{array}$ & $\begin{array}{r}.368 \\
<.001 \\
.007\end{array}$ \\
\hline $\begin{array}{l}\text { Family medical history } \\
\text { Hypertension } \\
\text { Hypertriglyceridemia } \\
\text { Low HDL-C } \\
\text { Diabetes mellitus }\end{array}$ & $\begin{array}{r}1,129(27.2) \\
891(21.5) \\
1,084(26.1) \\
396(9.7)\end{array}$ & $\begin{array}{l}583(26.2) \\
514(23.1) \\
601(27.0) \\
221(9.9)\end{array}$ & $\begin{array}{l}546(28.4) \\
377(19.6) \\
483(25.1) \\
175(9.1)\end{array}$ & $\begin{array}{l}1.95 \\
5.74 \\
1.49 \\
0.40\end{array}$ & $\begin{array}{l}.163 \\
.017 \\
.223 \\
.529\end{array}$ \\
\hline $\begin{array}{l}\text { Lifestyle } \\
\text { Smoking (yes) } \\
\text { Alcohol drinking (yes) }\end{array}$ & $\begin{array}{r}785(18.9) \\
1,532(36.9)\end{array}$ & $\begin{array}{l}572(25.7) \\
897(40.3)\end{array}$ & $\begin{array}{l}213(11.1) \\
635(33.0)\end{array}$ & $\begin{array}{l}71.99 \\
13.05\end{array}$ & $\begin{array}{l}<.001 \\
<.001\end{array}$ \\
\hline Walking hours/week & $40.31 \pm 1.04$ & $40.69 \pm 1.37$ & $39.89 \pm 1.52$ & 0.40 & .690 \\
\hline $\begin{array}{l}\text { Frequency of meals/day } \\
\text { Once } \\
\text { Twice } \\
\text { Three times }\end{array}$ & $\begin{array}{c}232(5.6) \\
1,248(30.1) \\
2,669(64.3)\end{array}$ & $\begin{array}{r}103(4.6) \\
652(29.3) \\
1,471(66.1)\end{array}$ & $\begin{array}{r}129(6.7) \\
596(31.0) \\
1,198(62.3)\end{array}$ & 6.88 & .032 \\
\hline $\begin{array}{l}\text { Weight control effort over the past year } \\
\text { Loss } \\
\text { Maintain } \\
\text { Gain } \\
\text { Never tried }\end{array}$ & $\begin{array}{r}1,509(36.4) \\
702(16.9) \\
441(10.6) \\
1,497(36.1)\end{array}$ & $\begin{array}{l}586(26.3) \\
356(16.0) \\
353(15.9) \\
930(41.8)\end{array}$ & $\begin{array}{c}923(47.9) \\
346(18.0) \\
88(4.6) \\
567(29.5)\end{array}$ & 231.35 & $<.001$ \\
\hline Sleeping hours/day & $7.11 \pm 0.03$ & $7.24 \pm 0.04$ & $6.94 \pm 0.05$ & 4.94 & $<.001$ \\
\hline Psychological & & & & & \\
\hline $\begin{array}{l}\text { Perceived body shape } \\
\text { Thin } \\
\text { Average } \\
\text { Fat }\end{array}$ & $\begin{array}{l}1,042(25.1) \\
1,750(42.2) \\
1,357(32.7)\end{array}$ & $\begin{array}{l}723(32.5) \\
808(36.3) \\
695(31.2)\end{array}$ & $\begin{array}{l}319(16.6) \\
942(49.0) \\
662(34.4)\end{array}$ & 108.25 & $<.001$ \\
\hline $\begin{array}{l}\text { Perceived stress level } \\
\text { Very high } \\
\text { High } \\
\text { Low } \\
\text { Almost none }\end{array}$ & $\begin{array}{r}145(3.5) \\
877(21.1) \\
2,475(59.7) \\
652(15.7)\end{array}$ & $\begin{array}{r}51(2.3) \\
425(19.1) \\
1,359(61.0) \\
391(17.6)\end{array}$ & $\begin{array}{r}94(4.9) \\
452(23.5) \\
1,116(58.0) \\
261(13.6)\end{array}$ & 23.76 & $<.001$ \\
\hline
\end{tabular}

*Sample size, estimated population represented in millions (adjusted complex sampling weight); BMI, body mass index; DBP, diastolic blood pressure FPG, fasting plasma glucose; HDL-C, high-density lipoprotein-cholesterol; SBP, systolic blood pressure; TG, triglyceride; WC, waist circumference; WHtR, waist-to-height ratio (waist/height). 
WC, SBP, DBP, and FPG were significantly higher in boys than girls, but HDL-C levels were higher in girls than in boys, though those anthropometric variables were within the normal range. The prevalence of a relevant family medical history (hypertriglyceridemia) and certain lifestyle factors (smoking, alcohol drinking, sleeping) were significantly higher in boys than in girls. The frequency of meals per day, weight control efforts over the past year, perceived body shape, and perceived stress levels were also significantly different according to gender.

\section{Estimated Prevalence of Metabolic Syndrome Com- ponents by Gender}

Gender differences in the estimated prevalence of MetS and its components are shown in Table 2. Among the components of metabolic abnormalities, elevated BP $\left(x^{2}=4.94, p=.026\right)$ and low HDL-C $\left(x^{2}=21.02, p<.001\right)$ were significantly more common in boys than in girls, whereas abdominal obesity was significantly more common in girls than in boys $\left(x^{2}=3.86, p=\right.$ .049). The estimated mean prevalence of MetS was $4.2 \%$ of all South Korean children and adolescents. The prevalence of MetS was $4.8 \%$ in boys and $3.4 \%$ in girls, and it did not significantly differ by gender $\left(x^{2}=3.40, p=.065\right)$.

\section{Estimated Prevalence of Metabolic Syndrome by Age and its Gender Differences}

Figure 1 shows changes in the estimated prevalence of MetS by age from 10 to 18 years. The overall incidence among children and adolescents ranged from $2.5 \%$ to $3.3 \%$ at the ages of 10-12 years but increased gradually to $3.5 \%$ to $5.5 \%$ after the age of 13 . However, the prevalence by gender showed a somewhat different pattern from the trend of the overall results. From 10 to 12 years old, the prevalence of MetS was lower in boys $(2.0 \%-2.6 \%)$ than in girls $(3.0 \%-4.0 \%)$. However, after the age of 13 , the prevalence of MetS in boys $(4.2 \%-6.8 \%)$ was higher than that in girls $(1.7 \%-4.2 \%)$. The difference in prevalence by gender was most significant at 13 years old $\left(x^{2}=4.57\right.$, $p=.033$ ). The prevalence in boys increased sharply at 13 years of age (up to $5.2 \%$ ), and although it decreased slightly at 14 and 17 years, it steadily increased from $4.2 \%$ to $6.8 \%$ from 13 to 18 years of age. The prevalence of MetS in girls increased from 10 to 11 years of age (up to $4.0 \%$ ) and dropped sharply up to the age of 13 (down to $1.7 \%$ ). It then gradually increased up to $4.2 \%$ at 17 years and decreased again at 18 years of age (down to $2.9 \%)$.

\section{Factors Associated with Metabolic Syndrome Using Univariate Logistic Regression Analysis by Gender}

The adjusted OR by exploratory analysis of MetS-associated factors in South Korean children and adolescents by gender are shown in Table 3. In the total study population, the prevalence of MetS significantly increased with age, BMI, WHtR, WC, SBP, DBP, TG, HDL-C, and FPG. The prevalence of MetS was also higher among subjects who had a familial medical history of low HDL-C, made efforts over the past year to lose and maintain weight, and reported a perceived body shape of "fat".

There were, however, some gender differences in factors associated with MetS. Common associated factors in both genders were a high $\mathrm{BMI}(\mathrm{OR}=1.47, \mathrm{OR}=1.42$; values presented in boys and in girls, respectively), a $\mathrm{WH} t \mathrm{R} \geq 0.5(\mathrm{OR}=27.59, \mathrm{OR}=$

Table 2. Prevalence of Metabolic Syndrome Components by Gender $(N=4,149)$

\begin{tabular}{|c|c|c|c|c|c|c|}
\hline \multirow[t]{2}{*}{ Variables } & \multirow[t]{2}{*}{ Categories } & $\begin{array}{c}\text { Total } \\
\left(N=4,149,4.6 \mathrm{~m}^{*}\right)\end{array}$ & $\begin{array}{c}\text { Boys } \\
\left(n=2,226,2.4 m^{*}\right)\end{array}$ & $\begin{array}{c}\text { Girls } \\
\left(\mathrm{n}=1,923,2.1 \mathrm{~m}^{*}\right)\end{array}$ & \multirow[t]{2}{*}{$x^{2}$} & \multirow[t]{2}{*}{$p$} \\
\hline & & $N(\%)$ & $\mathrm{n}(\%)$ & $\mathrm{n}(\%)$ & & \\
\hline $\begin{array}{l}\text { Prevalence of metabolic } \\
\text { syndrome and } \\
\text { components }\end{array}$ & $\begin{array}{l}\text { Abdominal obesity } \\
\text { Elevated } \mathrm{BP}^{\dagger} \\
\text { High TG } \\
\text { Low HDL-C } \\
\text { High FPG }\end{array}$ & $\begin{array}{r}415(10.0) \\
1,143(27.5) \\
618(14.5) \\
481(11.6) \\
27(0.7)\end{array}$ & $\begin{array}{l}200(9.0) \\
649(29.2) \\
249(11.2) \\
314(14.1) \\
13(0.6)\end{array}$ & $\begin{array}{c}215(11.2) \\
494(25.7) \\
369(19.2) \\
167(8.7) \\
14(0.7)\end{array}$ & $\begin{array}{r}3.86 \\
4.94 \\
1.33 \\
21.02 \\
0.08\end{array}$ & $\begin{array}{r}.049 \\
.026 \\
.249 \\
<.001 \\
.775\end{array}$ \\
\hline $\begin{array}{l}\text { Number of metabolic } \\
\text { abnormalities }\end{array}$ & $\begin{array}{l}\geq 1 \\
\geq 2 \\
\geq 3 \\
\geq 4\end{array}$ & $\begin{array}{c}2,029(48.9) \\
660(15.9) \\
173(4.2) \\
36(0.9)\end{array}$ & $\begin{array}{c}1,129(50.8) \\
381(17.1) \\
107(4.8) \\
22(1.0)\end{array}$ & $\begin{array}{c}900(46.8) \\
279(14.5) \\
66(3.4) \\
14(0.7)\end{array}$ & $\begin{array}{l}4.96 \\
3.60 \\
3.40 \\
0.95\end{array}$ & $\begin{array}{l}.026 \\
.058 \\
.065 \\
.329\end{array}$ \\
\hline Metabolic syndrome & & $173(4.2)$ & $107(4.8)$ & $66(3.4)$ & 3.40 & .065 \\
\hline
\end{tabular}

*Sample size, estimated population represented in millions (adjusted complex sampling weight); ${ }^{\dagger}$ Waist circumference $\geq$ age-, gender-specific 90 th percentile; ${ }^{\dagger}$ Elevated blood pressure $\geq$ age-, gender-specific 90 th percentile; ${ }^{8}$ High triglycerides $\geq 110 \mathrm{mg} / \mathrm{dL}$; "Low high-density lipoproteincholesterol $\leq 40 \mathrm{mg} / \mathrm{dL}$; "High fasting plasma glucose $\geq 110 \mathrm{mg} / \mathrm{dL} ; \mathrm{BP}$, blood pressure; FPG, fasting plasma glucose; HDL-C, high-density lipoprotein-cholesterol; TG, triglyceride. 


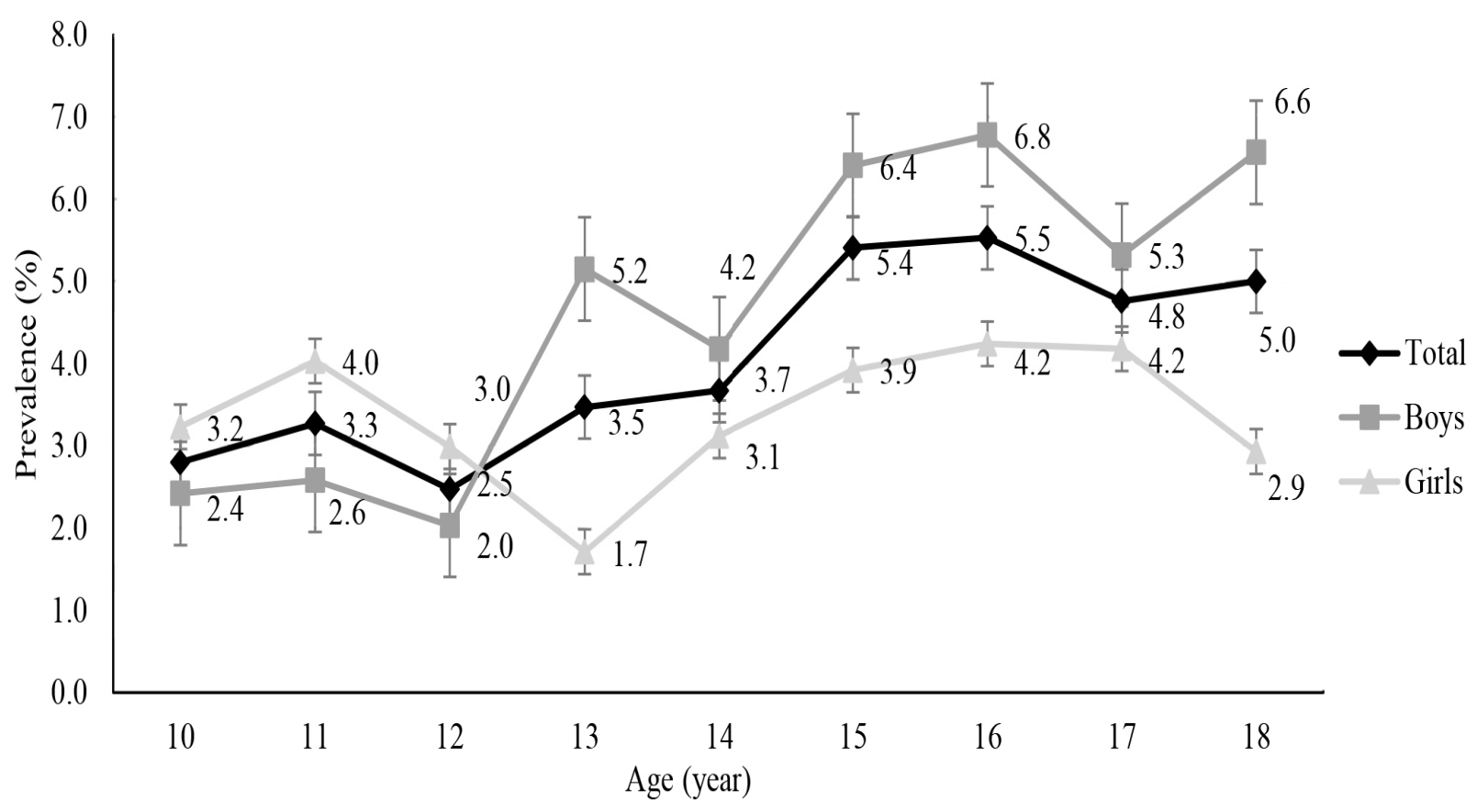

Figure 1. The prevalence of metabolic syndrome by age and gender. $p<.050$.

26.99), high $\mathrm{WC}(\mathrm{OR}=1.16, \mathrm{OR}=1.19)$, high $\mathrm{SBP}(\mathrm{OR}=1.10$, $\mathrm{OR}=1.12)$, high $\mathrm{DBP}(\mathrm{OR}=1.13, \mathrm{OR}=1.12)$, high $\mathrm{TG}(\mathrm{OR}=1.02$, $\mathrm{OR}=1.02)$, high HDL-C $(\mathrm{OR}=0.82, \mathrm{OR}=0.83)$, reported weight loss attempts $(\mathrm{OR}=5.02, \mathrm{OR}=3.18)$, and a reported perceived body shape of "fat"(OR=7.09, $\mathrm{OR}=10.73)$. Increasing age (OR= 1.14) and eating a meal once per day as opposed to three times per day $(\mathrm{OR}=2.66)$ were significant associated factors unique to boys. Increasing FPG $(\mathrm{OR}=1.06)$, having a familial medical history of low HDL-C (OR=2.02), and having a perceived "thin" body shape $(\mathrm{OR}=0.06)$ were significant associated factors unique to girls.

\section{DISCUSSION}

Among the estimated population of children and adolescents (4.6 million) in South Korea, the total prevalence of MetS was $4.2 \%$ in 2010-2015. This is much lower than in the United States, which had a $9.8 \%$ rate of MetS in children and adolescents from 1999 to 2012 [14], but slightly higher than in China, which had a rate of $3.4 \%$ in 2009 [20]. Despite the steady increase in the prevalence of obesity among Korean children and adolescents [11], the prevalence of MetS found in this study $(4.2 \%)$ is lower than the previous results of $7.1 \%$ in 2001 [12] and $6.2 \%$ in 2008-2014 [10]. This could have been because of the recent decrease in the rate of hypertension and hyperglycemia among South Korean children and adolescents compared to other MetS components [21], or because of the ag- gressive efforts by various national health care programs in South Korea to modify the lifestyles of children and adolescents by increasing physical activity and decreasing caloric intake [22]. However, considering that MetS in childhood increases the risk and prevalence of type 2 diabetes mellitus and atherosclerotic cardiovascular disease in adulthood [2], health care providers should be vigilant about the threat of MetS in children and adolescents.

The prevalence of MetS was not statistically different by gender in this study, but the prevalence was somewhat higher in boys than in girls ( $4.8 \%$ in boys, $3.4 \%$ in girls). The finding of a higher prevalence in boys is consistent with reports from other countries such as America, Norway, and China [4,20]. In this study, the high prevalence of MetS in boys could be explained by the differences between genders in the rates of three metabolic components (abdominal obesity, elevated BP, and low HDL-C). Specifically, of the five metabolic components, the rates of elevated BP and low HDL-C were significantly higher in boys. Barstad et al. [23] found that boys were more likely to have an unhealthy lifestyle than girls, including consuming more calories and being less physically active, which puts boys at a higher risk for obesity. In the current study, we found that boys who ate one meal per day were 2.66 times more likely to have MetS than boys who ate three meals per day. These results are similar to those of Moon's study [9], which reported that skipping meals could lead to increased snack consumption or binge eating, resulting in increased 
Table 3. Associated Factors of Metabolic Syndrome by Univariate Logistic Regression $(N=4,149)$

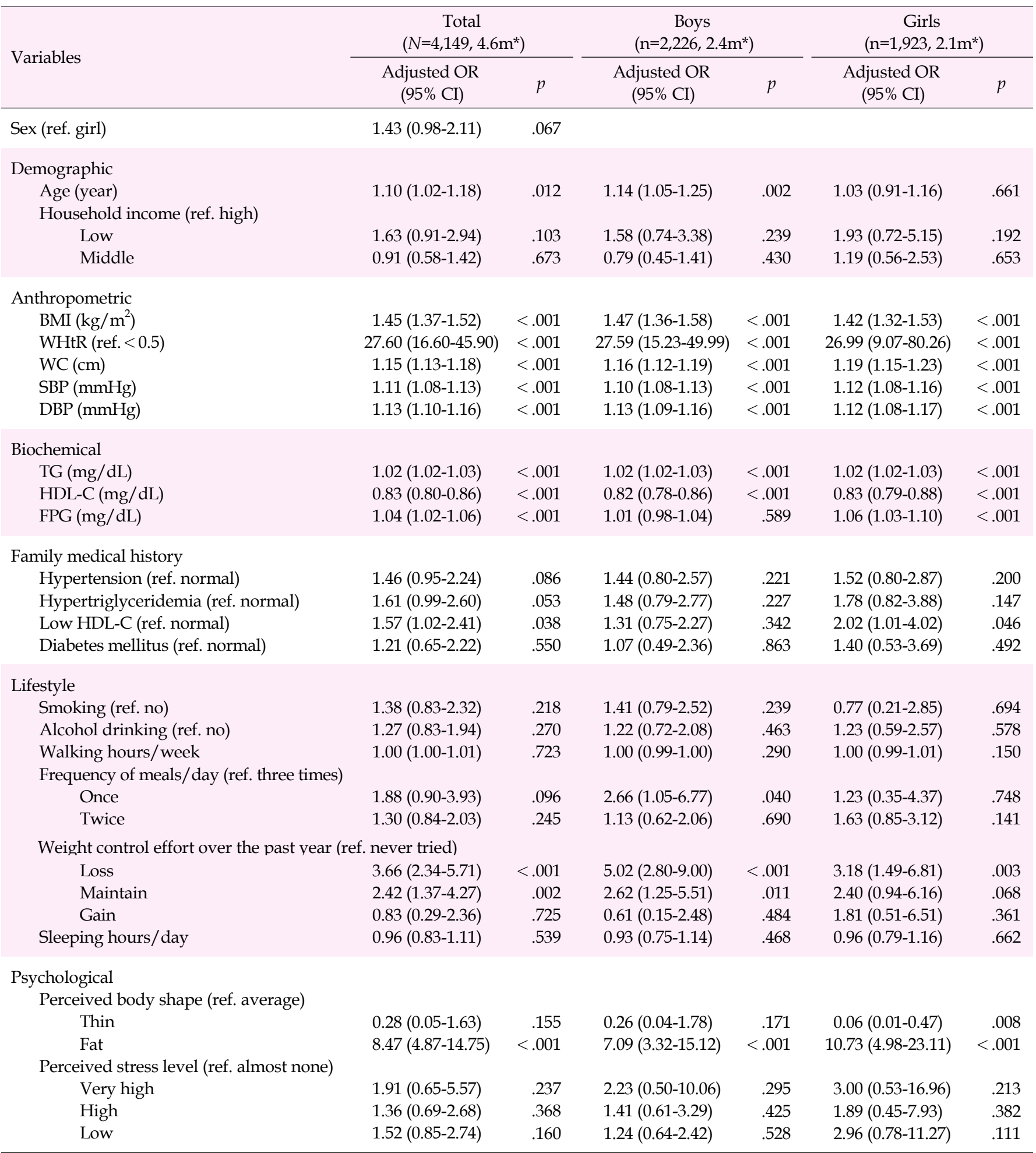

*Sample size, estimated population represented in millions (adjusted complex sampling weight); BMI, body mass index; CI, confidence interval; DBP, diastolic blood pressure; FPG, fasting plasma glucose; HDL-C, high-density lipoprotein-cholesterol; OR, odds ratio; SBP, systolic blood pressure; TG, triglyceride; WC, waist circumference; WHtR, waist-to-height ratio (waist/height).

obesity or hyperlipidemia. Therefore, interventions for boys with MetS need to be developed strategically and emphasize the importance of regular eating habits instead of binge eating. Only one metabolic component (WC) was significantly 
higher in girls than in boys. A higher prevalence of abdominal obesity in girls was also observed in previous studies of South Korean and American teenagers [11,24]. However, a Chinese study showed the opposite result that prevalence of abdominal obesity was higher in boys [20]. Although contradictory results have been reported for abdominal obesity by gender, abdominal obesity is the best indirect predictor of visceral fat accumulation, which is affected by pubertal hormone changes $[24,25]$. Pubertal hormone changes lead to increased fat mass, lean body mass, blood pressure, and lipid levels, which are MetS components [2]. Increased WC in girls is a particular concern because abdominal obesity can lead to obesity, type 2 diabetes mellitus, or MetS in adult women [2]. Active interventions to reduce abdominal obesity in girls are also essential because girls who have abdominal obesity in adolescence are at a higher risk of being overweight while pregnant, developing gestational diabetes mellitus, and giving birth to overweight offspring [26]. However, we could not distinguish the effect each stage of puberty had on the prevalence of metabolic components since the dataset used did not have information on individuals' pubertal stages. Therefore, additional research would be needed to identify gender differences in abdominal obesity considering puberty-related hormone changes.

Gender differences were also observed when analyzing MetS prevalence by age. First, during the pre-puberty or early puberty period, the prevalence of MetS in girls was higher than in boys. However, within the age range of middle and late puberty, its prevalence in boys was higher than in girls until the end of adolescence. Similar findings in another study showed a higher rate of MetS in boys during puberty [27]. One could infer from these results that one of the reasons why MetS prevalence in boys continues to rise throughout childhood and adolescence is that boys tend to be less interested in their personal appearance than girls due to a greater degree of social acceptance for male obesity in South Korea [8] and a low compliance with obesity management programs [23]. Considering this, in addition to the results of previous studies that found that boys in South Korea were less likely to undertake weight management measures [28], interventions to prevent and manage MetS in boys should consider focusing on motivational strategies. Secondly, two points in time showed significant gender differences in the prevalence of MetS, with a sharp increase in boys at 13 and a sharp decrease observed in girls at 18. A South Korean study [28] that analyzed the eating habits of South Korean male middle school students showed that unbalanced eating habits and binge eating due to stress were more severe in boys. As a result, though boys' levels of exercise were similar to those of girls, the proportion of overweight boys was higher [28]. This finding supports the sharp increase in MetS prevalence among boys 13 and older ob- served in this study. In contrast, girls at 13 years old, when the prevalence of MetS first decreases among girls, are just entering junior high school tend to become more interested in their personal appearance and body image, and thus are more likely to try to lose weight than boys [8]. When prevalence decreases again in girls at 18 years old, girls may put effort into losing weight ahead of entering college or searching for a job [29]. Notably, the social expectation in South Korea for women to maintain their appearance and have a slim body [29] might have an influence on women's likelihood of making weight control efforts and, consequently, the decrease in the prevalence of MetS in girls at the late stages of puberty. Considering the different ages at which rapid increases and decreases in MetS prevalence according to gender were observed, different strategies for boys and girls regarding the timing of interventions should be considered. Thirdly, the gender differences in prevalence by age showed quite different patterns. This indicates that interventions with gender-specific approaches are more likely to be effective. For example, boys from the ages of 12 to 17 years and girls from the ages of 10 and 13 years (immediately before an overall rise in MetS prevalence) should be more closely monitored and targeted for gender-specific preventive interventions.

As in previous studies, we also found significant associations of MetS with BMI and WHtR. As BMI increased, the prevalence of MetS increased by 1.47 times in boys and 1.42 times in girls. BMI is a well-known significant predictor of MetS [9, 30]. Therefore, it would be a useful indicator in outpatient or community settings for the early detection of MetS in highrisk children and adolescents. The impact of increasing WHtR on MetS prevalence was also confirmed in the current study and others [10]. In this study, the prevalence of MetS was 27.59 times higher in boys and 26.99 times higher in girls with a high WHtR, and a previous study found that WHtR was a better predictor of cardiac metabolic risk than BMI or WC [10]. WHtR is a definitive index correlated with visceral fat accumulation, and it is easy to track along with BMI at various ages. It also has the advantage of high gender consistency and is an easy indicator for follow-up in clinical and community settings. Considering the high relevance between BMI, WHtR, and MetS in these results, BMI and WHtR should be regarded as additional key predictors of MetS (as well as biochemical data) in children and adolescents, which makes the risk of MetS easier to assess in homes, schools, and community settings. Instead of expensive biochemical lab tests, these easily-observed features of the body may suggest cost-effective alternative interventions program for low-resource individuals or groups and would eliminate the discomfort of having blood drawn in children and adolescents.

Lastly, regarding the psychological aspects of the associa- 
tion between body shape perception, weight loss efforts, and MetS prevalence, this study discovered insights for MetS management for both genders. Results showed that the prevalence of MetS was higher for both genders among those who tried losing weight compared to those who did not (5.02 times higher in boys, 3.18 times higher in girls). MetS prevalence was also higher in the group that perceived their body shape as fat compared to average in both genders (7.09 times higher in boys, 10.73 times higher in girls). These results suggest that South Korean children and adolescents with MetS pay close attention to their body shape and lose weight by themselves. Considering the growth and developmental characteristics of children and adolescents [22], rather than simply restricting calorie intake to alter one's body shape and lose weight, a balanced diet and increased physical activity should be considered to manage these MetS components for healthy growth and development during childhood and adolescence. Therefore, well-guided, gender-specific interventions tailored to specific growth and developmental points will have a high impact on reducing the prevalence of MetS in this population.

The strength of this study is in its integration and analyses of multi-year national health survey data. The data, gathered over 6 years, made it possible to determine the average characteristics of representative subjects. Furthermore, by identifying differences in the characteristics, prevalence, and associated factors of MetS in children and adolescents by age and gender, this study found that age-specific and gender-specific health care interventions must be performed for effective MetS reduction and management. The study is limited, however, in identifying temporal and sequential relationships since it used secondary data that did not include variables enabling the identification the unique characteristics of MetS prevalence by pubertal stage. Therefore, the results should be interpreted with caution and causality should not be inferred. In the future, we suggest longitudinal studies that consider pubertal growth and development characteristics, gender specificity, and other variables (physical, psychological, social, and behavioral) that may influence MetS prevalence in children and adolescents.

\section{CONCLUSION}

The prevalence of MetS was $4.2 \%$ (4.8\% in boys, 3.4\% in girls) among South Korean children and adolescents. The prevalence of MetS was not statistically different by gender in this study, but gender differences were identified in the prevalence of MetS components (abdominal obesity, elevated BP, and low HDL-C), changes in age-specific prevalence patterns (higher in girls until 12 years of age, but higher in boys after 13 years of age), and associated multifaceted risk factors of MetS (physical, psychological, and lifestyle characteristics). Gender and age differences should be considered to understand MetS in South Korean children and adolescents and to develop effective intervention programs to prevent and manage MetS in this population.

\section{ORCID}

Jihea Choi

Tae Woong Yoon

Min Heui Yu

Dae Ryong Kang

Sarah Choi https://orcid.org/0000-0003-1881-6342

https://orcid.org/0000-0003-3265-9785

https://orcid.org/0000-0003-3787-795X

https://orcid.org/0000-0002-8792-9730

https://orcid.org/0000-0003-3459-716X

\section{Authors' contribution}

Conceptualization: Jihea Choi, Dae Ryong Kang; Data curation, Formal analysis: all authors; Writing-original draft, Writing-review and editing: all authors; Final approval of published version: all authors.

\section{Conflict of interest}

No existing or potential conflict of interest relevant to this article was reported.

\section{Funding}

This study was supported by a National Research Foundation of Korea (NRF) grant funded by the Korean government (MSIT) (No. NRF-2017R1C1B5076837).

\section{Data availability}

Please contact the corresponding author for data availability.

\section{Acknowledgements}

None.

\section{REFERENCES}

1. Graf C, Ferrari N. Metabolic syndrome in children and adolescents. Visceral Medicine. 2016;32(5):357-362. https://doi.org/10.1159/000449268

2. Agirbasli M, Tanrikulu AM, Berenson GS. Metabolic syndrome: Bridging the gap from childhood to adulthood. Cardiovascular Therapeutics. 2016;34(1):30-36.

https://doi.org/10.1111/1755-5922.12165

3. The GBD 2015 Obesity Collaborators. Health effects of overweight 
and obesity in 195 countries over 25 years. New England Journal of Medicine. 2017;377(1):13-27.

https://doi.org/10.1056/NEJMoa1614362

4. DeBoer MD. Assessing and managing the metabolic syndrome in children and adolescents. Nutrients. 2019;11(8):1788. https://doi.org/10.3390/nu11081788

5. Pereira S, Santos C, Katzmarzyk PT, Maia J. Familial resemblance in body shape and composition, metabolic syndrome, physical activity and physical fitness: A summary of research in Portuguese families and siblings. Twin Research and Human Genetics. 2019;22 (6):651-659. https://doi.org/10.1017/thg.2019.46

6. Magge SN, Goodman E, Armstrong SC. The metabolic syndrome in children and adolescents: Shifting the focus to cardiometabolic risk factor clustering. Pediatrics. 2017;140(2):e20171603. https://doi.org/10.1542/peds.2017-1603

7. Rochlani Y, Pothineni NV, Mehta JL. Metabolic syndrome: Does it differ between women and men? Cardiovascular Drugs and Therapy. 2015;29(4):329-338.

https://doi.org/10.1007/s10557-015-6593-6

8. Kim BH, Choi JH. Perceived body image, intentional caloric restriction and physical manifestations of unbalanced nutrition according to body mass index in fifth and sixth grade elementary school students. Child Health Nursing Research. 2009;15(4):359366. https://doi.org/10.4094/jkachn.2009.15.4.359

9. Moon WJ. The relation among adolescents metabolic syndrome, dietary life, physical activity and mental health-using 7th national nutrition survey of 1st year(2016). Journal of Korea AcademiaIndustrial Cooperation Society. 2019;20(6):158-168.

https://doi.org/10.5762/KAIS.2019.20.6.158

10. Choi DH, Hur YI, Kang JH, Kim K, Cho YG, Hong SM, et al. Usefulness of the waist circumference-to-height ratio in screening for obesity and metabolic syndrome among Korean children and adolescents: Korea National Health and Nutrition Examination Survey, 2010-2014. Nutrients. 2017;9(3):256.

https://doi.org/10.3390/nu9030256

11. Bang SY. Prevalence and related factors of metabolic syndrome in Korean adolescent. Journal of Korea Academia-Industrial Cooperation Society. 2018;19(3):309-316.

https://doi.org/10.5762/KAIS.2018.19.3.309

12. Seo MJ, Seong JW, Sohn KJ, Ko BJ, Han JH, Kim SM. Prevalence of the metabolic syndrome in Korean children and adolescents: Korea National Health and Nutrition Survey 2001. Journal of the Korean Academy of Family Medicine. 2006;27(10):798-806.

13. Newsis. 1 in 3 people is obese. OECD "Korean high obesity doubles by 2030" [Internet]. Seoul: Newsis; 2018 [cited 2020 March 25]. Available from:

https://www.newsis.com/view?id=NISX20180726_0000374805

14. Lee AM, Gurka MJ, DeBoer MD. Trends in metabolic syndrome severity and lifestyle factors among adolescents. Pediatrics. 2016;137 (3):e20153177. https://doi.org/10.1542/peds.2015-3177
15. Kweon S, Kim Y, Jang MJ, Kim Y, Kim K, Choi S, et al. Data resource profile: The Korea national health and nutrition examination survey(KNHANES). International Journal of Epidemiology. 2014;43(1):69-77. https://doi.org/10.1093/ije/dyt228

16. Cook S, Weitzman M, Auinger P, Nguyen M, Dietz WH. Prevalence of a metabolic syndrome phenotype in adolescents: Findings from the third National Health and Nutrition Examination Survey, 1988-1994. Archives of Pediatrics and Adolescent Medicine. 2003; 157(8):821-827. https://doi.org/10.1001/archpedi.157.8.821

17. Moon JS, Lee SY, Nam CM, Choi JM, Choe BK, Seo JW, et al. 2007 Korean national growth charts: Review of developmental process and an outlook. Korean Journal of Pediatrics. 2008;51(1):1-25. https://doi.org/10.3345/kjp.2008.51.1.1

18. Arora T, Agouba S, Sharara A, Taheri S, Arora T. The role of genetic, dietary and lifestyle factors in pediatric metabolic syndrome: A review of the literature from prenatal to adolescence. Arab Journal of Nutrition and Exercise. 2017;2(1):1-22.

https://doi.org/https://doi.org/10.18502/ajne.v2i1.1241

19. Lee $H$. The effects of lifestyle factors on metabolic syndrome among adolescents. 2014;28(2):270-284.

https://doi.org/https://doi.org/10.5932/JKPHN.2014.28.2.270

20. Song P, Yu J, Chang X, Wang M, An L. Prevalence and correlates of metabolic syndrome in Chinese children: The China Health and Nutrition Survey. Nutrients. 2017;9(1):79.

https://doi.org/10.3390/nu9010079

21. Lee KH, Chong CU. Prevalence and 10-year trend of metabolic syndrome in Korean children and adolescents: 1998-2008 Korean National Health and Nutrition Examination Survey. Asian Journal of Beauty and Cosmetology. 2010;8(4):1-9.

22. Seo YG, Lim H, Kim YM, Ju YS, Lee HJ, Jang HB, et al. The effect of a multidisciplinary lifestyle intervention on obesity status, body composition, physical fitness, and cardiometabolic risk markers in children and adolescents with obesity. Nutrients. 2019;11(1):137. https://doi.org/10.3390/nu11010137

23. Barstad LH, Júlíusson PB, Johnson LK, Hertel JK, Lekhal S, Hjelmesæth J. Gender-related differences in cardiometabolic risk factors and lifestyle behaviors in treatment-seeking adolescents with severe obesity. BMC Pediatrics. 2018;18(1):61.

https://doi.org/10.1186/s12887-018-1057-3

24. Park J, Hilmers DC, Mendoza JA, Stuff JE, Liu Y, Nicklas TA. Prevalence of metabolic syndrome and obesity in adolescents aged 12 to 19 years: Comparison between the United States and Korea. Journal of Korean Medical Science. 2010;25(1):75-82. https://doi.org/10.3346/jkms.2010.25.1.75

25. Brambilla P, Bedogni G, Moreno LA, Goran MI, Gutin B, Fox KR, et al. Crossvalidation of anthropometry against magnetic resonance imaging for the assessment of visceral and subcutaneous adipose tissue in children. International Journal of Obesity. 2006;30:23-30. https://doi.org/10.1038/sj.ijo.0803163

26. Pirkola J, Pouta A, Bloigu A, Hartikainen AL, Laitinen J, Järvelin 
MR, et al. Risks of overweight and abdominal obesity at age 16 years associated with prenatal exposures to maternal prepregnancy overweight and gestational diabetes mellitus. Diabetes Care. 2010;33(5):1115-1121. https://doi.org/10.2337/dc09-1871

27. Agirbasli M, Agaoglu NB, Orak N, Caglioz H, Ocek T, Poci N, et al. Sex hormones and metabolic syndrome in children and adolescents. Metabolism: Clinical and Experimental. 2009;58(9):1256-1262. https://doi.org/10.1016/j.metabol.2009.03.024

28. Lee NY, Lee SK. Subjective body image perception, obesity stress, and dietary habits according to gender among middle school stu- dents. Keimyung Journal of Nursing Science. 2017;21(1):65-75

29. Choi MH. The effect of body mass index(BMI) on body image, stress, happiness of normal-weight female adolescents: Focus on double-mediator effect of body image and stress. Journal of Regional Policies. 2017;28(2):127-151.

30. Morrison JA, Friedman LA, Gray-McGuire C. Metabolic syndrome in childhood predicts adult cardiovascular disease 25 years later: The Princeton Lipid Research Clinics Follow-up Study. Pediatrics. 2007;120(2):340-345. https://doi.org/10.1542/peds.2006-1699 